\title{
CORPO-COLÔNIA: UM ESTUDO PRELIMINAR SOBRE A REPRESENTAÇÃO DAS MULHERES NEGRAS AFRICANAS DURANTE A GUERRA COLONIAL A PARTIR DE QUE SE PASSA NA FRENTE DE AUGUSTO CID
}

\author{
Paolo La Valle ${ }^{1}$
}

\begin{abstract}
Resumo
O trabalho apresenta-se como um estudo preliminar sobre a representação das mulheres negras em Portugal durante os anos da guerra colonial (1961-1975). Seguindo as sugestões dos atuais movimentos globais de mulheres (Ni una menos, Women's March, Non una di Meno...) o artigo visa a investigar a dupla hierarquização sofrida pelas mulheres negras e, ao mesmo tempo, analisar como e se as resistências contra o fascismo e o colonialismo português influíram nessas representações. As imagens das mulheres negras em Portugal ao longo do século revelam corpos sexualizados, objetos à disposição dos colonizadores. Porém, centrando a reflexão em Bandas Desenhadas, é preciso lembrar, a partir de Luís Cunha (1995), como a representação dos homens negros em BDs mudou ao longo do século e sobretudo durante a guerra colonial. O artigo analisa os desenhos de Augusto Cid publicados em Que se passa na frente (1973), no intento de verificar se a guerra e as resistências levaram a algumas mudanças na representação das mulheres feita pelos colonizadores. Essas análises permitem refletir sobre como os estereótipos racistas e sexistas mudaram nos últimos anos do regime fascista português, construindo as bases para interrogar a sociedade do pós-25 de Abril e ver assim se os rastos destas violências chegam até hoje.
\end{abstract}

Palavras-chave: colonialismo, Banda Desenhada, estereótipo, mulheres, Augusto Cid.

\section{Body-Colony: a preliminary study about the representation of black women during colonial war, from Augusto Cid's perspective in Que se passa na frente}

\begin{abstract}
This work consists in a preliminary study about the representations of black women in Portugal during the colonial war (1961-1975). Following the ideas of current international women's movements (Ni una menos, Women's March, Non una di meno...) it is this article's main goal to investigate the double hierarchization suffered by black women, as well as analyze how and whether the resistances against Portuguese fascism and colonialism affected such representations. The images of black women in Portugal during the XXth century reveal sexualized bodies, objects available to the colonizer. However, by focusing our attention on Portuguese comics, it must be remembered, as we are told by Luís Cunha (1995), that black men representation in BD changed during the century, especially during the colonial war. This article analyzes Augusto Cid's illustration published in Que se passa na frente (1973), in order to investigate if war and the resistances induced changes on the colonizer's representation of black women. By analysing it, we are allowed to meditate upon how racist and sexist stereotypes changed in the last year of fascist Portuguese regime and therefore interrogate post-25 de Abril Portuguese society in order to understand if the traces of this violence are still present.
\end{abstract}

Keywords: colonialism, Banda Desenhada, stereotype, women, Augusto Cid

\footnotetext{
1 Professor contratista de Literatura portuguesa e brasileira na Universidade de Milão (IT). Professor contratista de Cultura e literatura portuguesa na Universidade de Catania (IT).
} 


\section{Introdução}

Como afirmam os historiadores, a visão sobre o passado depende sempre de como olhamos para o nosso presente e para os processos de construção da história ao longo dos anos (Cf. RICCEUR, 2008). Nesta reflexão, os conflitos sociais podem produzir rupturas, tornando visível o invisível, levando a uma nova visão do passado e influindo na construção de identidades e políticas, como perceberam os historiadores do século XIX (Cf. WHITE, 1973), e como já explicou Lukács ao analisar o romance histórico do século XIX (2011).

Nas recentes mobilizações internacionais de mulheres, a temática dos direitos é abordada nas suas inúmeras perspectivas que, a partir da centralidade feminina, olham a realidade segundo a ideia que o feminismo não é uma temática específica, mas sim "uma leitura global do existente" (NON UNA DI MENO, 2017). Os textos mais conhecidos ligados as essas mobilizações (principalmente o manifesto do movimento Ni Una Menos, pela convocatória de uma manifestação no dia 25 de Novembro 2016, e as declarações de numerosas intelectuais em ocasião das Women's marches do 21 de Janeiro 2017) propõem uma visão de feminismo aberta a uma perspectiva transnacional ("no mundo inteiro 80\% das vítimas de exploração sexual são mulheres", lê-se na chamada em português) e também a uma perspectiva interseccional que, desde a autobiografia de Angela Davis (1974) até as ativistas do Black Lives Matter, sempre interessou aos movimentos pelos direitos civis de um ponto de vista filosófico e militante. Nos estudos, nas declarações e nos manifestos políticos, essas reflexões criam ligações entre os ditos fenómenos da violência (de género e de raça) e as suas origens. Como afirmou Angela Davis no seu discurso em Washington no dia 8 de março de 2017: "history cannot be delated like web pages" (2017).

Por essa razão, neste trabalho, queremos abordar o assunto da representação das mulheres negras no contexto da guerra colonial portuguesa, ou seja, num contexto de forte conflitualidade, onde os colonizados e as colonizadas lutavam contra o domínio dos colonos. Sendo a luta colonial um processo de libertação até mesmo no nível do imaginário (Cf. FANON, 1972; SPIVAK, 1999), a representação do dominado e da dominada aparece como o campo de uma batalha em que todos participam. Diversos poemas de Noêmia de Souza, bem como de outras autoras, centram-se no corpo da mulher e na sua sobreposição com o corpo da "Mãe/Terra/África" (FONSECA, 2000, p. 228). Neste sentido o corpo das mulheres luta contra uma dupla hierarquização devida ao fato de elas serem vítimas do 
sistema colonial e do sistema patriarcal: o corpo das mulheres surge assim como centro da microfísica do poder (FOUCAULT, 1979), o lugar último onde o poder exerce a sua força e as representações do corpo da mulher revelam as características biopolíticas do domínio imperial português. Portanto, na nossa análise, será preciso entrecruzar dois tipos de reflexões: a primeira, sobre o papel que o fascismo português reservava às mulheres; a segunda, sobre as representações dos habitantes dos territórios coloniais.

Porém é preciso lembrar que os estereótipos não são fixos, mas sofrem os influxos das mudanças e dos conflitos existentes; a recente publicação de Revisão (ou seja a republicação de Visão, uma coleção das bandas desenhadas portuguesas dos anos setenta) recupera, sobretudo, as publicações pós-25 de Abril, ou seja, depois da ruptura com o fascismo e sua violência e com o colonialismo, levando à memória a atitude crítica dos ilustradores frente o passado e seu constrangimento. A Banda Desenhada de Augusto Cid, Que se passa na frente (1973), permite analisar as representações das mulheres negras africanas no meio dos conflitos, ou seja, nos anos da guerra nas colónias e nos anos em que emergem com mais força os "feminismos em Portugal” (TAVARES, 2008). É por isso que é possível questionar essas imagens e verificar se nelas é possível encontrar os rastos da influência das resistências que caracterizaram os últimos anos da ditadura.

\section{Representações dominantes e resistências}

Uma breve revisão da condição feminina durante o Estado Novo permite, por um lado, destacar a posição de subalternidade das mulheres portuguesas e, por outro, a atenção da propaganda e da administração fascista na construção de uma identidade feminina complacente ao regime. Em particular o Movimento Nacional Feminino (MNF), criado em 1961, após o inicio da guerra em Angola, destacava-se pelo seu papel de apoio às políticas do Estado Novo reproduzindo a sua atitude colonial e patriarcal. Como escrevem Anna Cova e António Costa Pinto (1997, p. 84),

o manifesto de criação, assinado por 25 mulheres, definia o MNF como uma associação destinada a congregar todas as mulheres portuguesas interessadas no «apoio moral e material aos que lutam pela integridade do nosso património pátrio». 
Já Margarida Calafate Ribeiro (2004, p. 10) comenta como a participação das mulheres portuguesas na "máquina" da guerra colonial é funcional à ideia de "masculinidade":

\begin{abstract}
a nossa guerra foi ainda terreno de afirmação dos ideais masculinos de guerra com a sua componente de crença na defesa da integridade da pátria e nos ideais guerreiros como parte essencial da formação da masculinidade e mesmo de uma espécie de teste de masculinidade com a "ida à tropa", vulgarizada na expressão popular: "a tropa fará de ti um homem". Desta forma, o papel masculino dependia dos papéis femininos no sistema de guerra, que incluíam as situações de esposas, namoradas, irmãs e, principalmente de mães.
\end{abstract}

Além do caso das "Madrinhas da guerra" (NEVES, 2001) e dos casos em que o Estado Novo promovia o homefront das mulheres portuguesas, Calafate Ribeiro sublinha a ida das mulheres para a África e a participação delas na vida das colônias: "essas mulheres seriam também testemunhas e, de alguma forma, cúmplices de um mundo de guerra, aparentemente reservado aos homens" (RIBEIRO, 2004, p. 24).

Apesar da capacidade do regime português de promover um movimento feminino de suporte à guerra, nos anos da afirmação dos movimentos feministas registra-se pelo menos um episódio de protesto contra a guerra colonial. Em 8 de março de 1970, no comunicado distribuído para as ativistas do Movimento Democrático das Mulheres (MDM), lê-se sobre a solidariedade das mulheres portuguesas com as mães africanas e com os seus filhos, considerados "homens que lutam pela independência das suas pátrias, submetidas como a nossa à exploração e miséria" (MDM, apud TAVARES, 2008, p. 160). Este tipo de solidariedade é inevitavelmente situada e cria uma ponte entre povos explorados (o povo português e os povos africanos eram explorados pelo mesmo regime, embora de maneira diversa e com diferentes graus de violência), bem como entre mulheres de nações e raças distintas. Se por um lado a representação da mulher africana como mãe reproduz a subalternidade dos papéis sociais atribuídos às mulheres (digna de solidariedade enquanto mãe e não enquanto sujeito em si), por outro, representa a emersão de uma representação diferente das anteriores que, como na análise de Edward Said sobre Salomé de Flaubert (SAID, 2003, p. 188), criavam uma associação direta entre colônias e sexo.

Um ponto de referência nesse sentido é representado pela Exposição Colonial organizada no Porto (1934), na qual, na verdade, a mulher negra é apresentada como objeto de grande valor do patrimônio colonial português. A exposição, visitada por 1,3 
milhões de pessoas, mostrava as fotos de Rosa (Rosinha, ou Rosita, Figura 1), uma mulher da Guiné fotografada nua e em poses eróticas. Segundo a análise de Isabel Morais (2010), as imagens restituíam uma representação das colônias funcionais ao regime do Estado Novo, identificando os territórios coloniais como lugares desejáveis para os homens portugueses. Maria do Carmo Piçarra descreve um imaginário parecido ao escrever sobre os filmes do "cinema colonial", fortemente vinculados à censura do regime e, por isso, reprodutores de uma ideia de sociedade funcional ao Estado Novo. Em contraposição com a representação das mulheres portuguesas, o cinema mostra os corpos nus das mulheres africanas de algum modo incorrendo nos os estereótipos de disponibilidade e de promiscuidade sexual (2015, p. 182). As mulheres africanas diferenciavam-se assim das portuguesas que eram submetidas, ao longo dos anos do Estado Novo, a um rígido constrangimento moral. Como as outras sociedades ocidentais, também a sociedade portuguesa encontrava na sexualidade um elemento de excluisão para definir a sua própria identidade, um limite, como escrevia Michel Foucault, junto com o sonho, a loucura e a ideia de Oriente (GALZIGNA, 2011, p. 24).

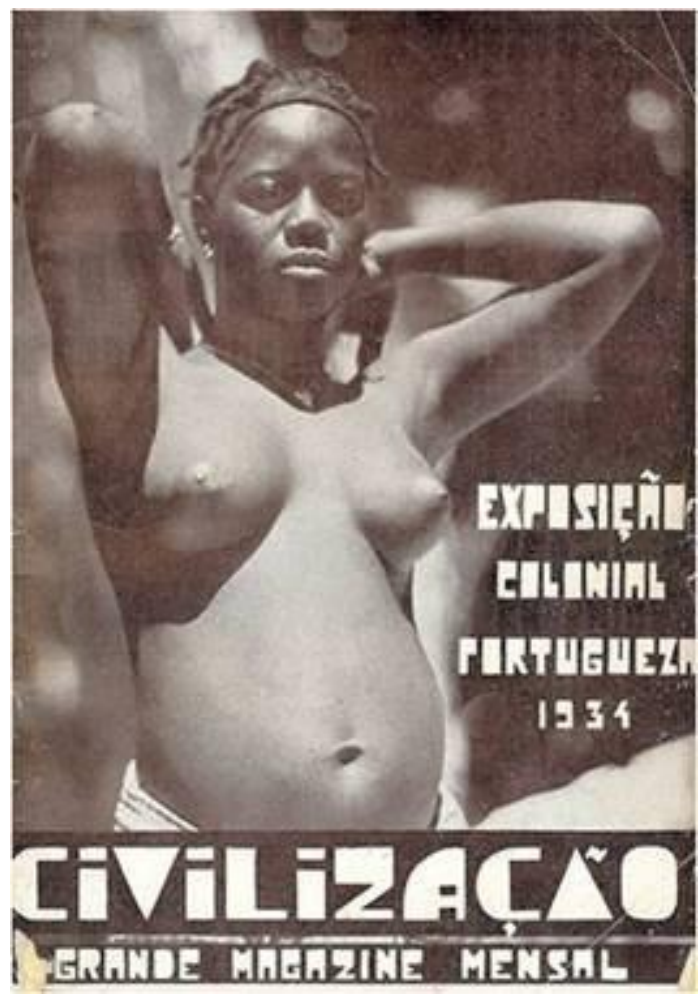

FIGURA 1. Uma das fotos de Rosita, presente na Exposição colonial e utilizada como material publicitário para o evento. 
A representação sexualizada das mulheres africanas fortifica-se por meio da teoria do luso-tropicalismo de Gilberto Freyre que o regime do Estado Novo utiliza conscientemente no intento de justificar os próprios domínios coloniais frente à cena internacional. As teorias de Gilberto Freyre abordam a temática das relações entre os portugueses-colonizadores e os povos colonizados, descrevendo como a identidade plurirracial do Brasil teve origem no estilo do colonialismo português, no qual a pacífica convivência entre colonizador, colonizado e colonizada assumia um papel central, sendo que as relações sexuais favoreciam um processo de miscigenação. Aparentemente o colonialismo português não excluía o Outro (a Outra) como os outros colonialismos, mas bem o (a) assimilava ao seu modelo. Claramente, nesta descrição, Freyre silencia os conflitos raciais do Brasil e o medo branco (AZEVEDO, 1987) que acompanhou a campanha pela abolição da escravidão, permitindo assim ao Estado Novo proporcionar ao mito dos "portugueses suaves", que já caracterizava a retórica de Salazar, uma base teórica para representar as relações entre colonizadores e colonizados na África de língua portuguesa. Por sua vez, as teorias de Freyre contribuem para formar a realidade, já que, como escreve Boaventura de Sousa Santos (2002, p. 18), no caso português "the sexist and interracial bed could become the basic unit of the empire's administration". A ideia da miscigenação era efetivamente um instrumento de domínio sobre os países africanos que consentia em minimizar os conflitos existentes frente à comunidade internacional e controlar os territórios além-mar.

A partir da década de 1960, o Estado Novo censurou e proibiu numerosos livros que forneciam uma representação das relações entre homens e mulheres diferentes daquela encorajada pelo regime (TAVARES, 2008, p. 156-157). Dentre estes, talvez o livro mais conhecido seja Novas Cartas Portuguesas, escrito pelas autoras Maria Isabel Barreno, Maria Teresa Horta e Maria Velho da Costa. O livro, publicado em 1972, foi censurado pelo regime e acusado de imoral e pornográfico. O caso tornou-se famoso em nível internacional, originando manifestações de solidariedade tanto na Europa como nos Estados Unidos. Atacando explicitamente o patriarcado português, as autoras dão a volta às relações homem-mulher, atacando os estereótipos da masculinidade, afirmando que "frágeis são os homens deste país de nostalgias idênticas e medos e desânimos" (BARRENO; HORTA; COSTA, 2011, p. 77). Mostravam, assim, as fraquezas dos homens portugueses e abriam uma brecha na representação que o regime de patriarcado do Estado 
Novo - assim como todos os grupos dominantes na sociedade ocidental já que "in Western society men are encouraged to dread, abhor, or deny feeling weak or helpless, whereas women are encouraged to cultivate this state of being" (MILLER, 1986, p. 27) oferecia de si.

Desta obra queremos assinalar dois elementos específicos. O primeiro é a crítica à guerra colonial, a diferença dos escritos de outras autoras, como Ana Castro Osório (1905) e Florbela Espanca (2009), que no início do século apelavam ao espírito patriótico das mulheres (e das mães) portuguesas. O segundo é a representação, presente em diversas cartas, dos homens como violentos "conquistadores", indiferentes aos desejos e às vontades das mulheres, tão longe da imagem dos "portugueses suaves" que a retórica salazarista promovia: "ó da minha posse na verdade te importas: eu tua terra, colónia, tua árvore-sombra programada para acalmar sentidos" (BARRENO, HORTA, COSTA, 2011, p. 21).

Este fragmento da "Primeira carta II" descreve o cruzamento de diferentes níveis de hierarquização: o corpo da mulher é visto não só como um território de conquista, mas bem como "colónia", utilizando uma palavra que se refere a um campo semântico especifico da dominação política. Numa única imagem, vemos incarnadas duas das relações de poder que, segundo Maria Mies, caracterizaram "the underground of capitalist patriarchy or civilized society" (MIES, 1999, p. 77). O problema da dominação da mulher por parte do homem, e mais especificadamente do corpo da mulher, apresenta-se também em outros fragmentos, embora isento desta conotação profundamente crítica a respeito da política portuguesa. Mesmo sem interceptar o problema da representação (e da posse) das mulheres africanas, as autoras ilustram uma hierarquia ao dizer que "um negro extremista é já respeitável, mas [...] uma feminista é vituperada, assustadora do ainda indiscursível, incómoda, ridícula, mesmo para os cavaleiros bem pensantes de toda a libertação" (BARRENO, HORTA, COSTA, 2011, p. 83). Melhor um terrorista (ou um combatente pela libertação do jogo colonial) do que uma mulher que recusa o patriarcado nacionalista. O feminismo apresenta-se assim como arma verdadeiramente revolucionária, capaz de derrubar um regime e criar novas utopias, fora do controle das ideologias existentes.

Porém, voltando mais uma vez à análise de Said sobre Salomé de Flaubert, é fácil evidenciar que do nosso discurso fica ausente a voz das mulheres africanas e em particular daquelas que lutaram pela libertação dos próprios países. Efetivamente, durante a guerra, 
algumas poetisas africanas exprimiram a própria subjetividade de mulheres negras combatentes, em alguns casos identificando o corpo da mulher com o corpo da sua própria nação ou com a África. Nesta forma, em numerosos poemas:

o imaginário ligado a terra, pátria, nação reforça com atributos femininos a idéia de origem, o lugar onde se nasceu, as alusões ao berço/colo "esplêndido" que nos embala. Não é de se estranhar, portanto, que imagens ligadas ao feminino sejam retomadas para se compor o corpo da nação, embora nem sempre seja a mulher a produtora dos discursos que tecem os contornos dessa comunidade imaginada, pensada como a grande casa que acolhe todos os seus filhos. (FONSECA, 2000, p. 226)

Podemos afirmar assim que existe uma contra-representação do corpo da mulher e uma reapropriação discursiva no âmbito das lutas de libertação e que (mesmo se os assuntos do desejo sexual e carnal tão presentes nas Novas Cartas Portugueses não conotem este tipo de produção, pelo menos nesta fase) esta produção abre outra brecha no sistema de domínio português, ligando a violência masculina e o patriarcado às políticas coloniais. Em "Se me quiseres conhecer", um poema posterior a este período, Noémia de Sousa (2001) escreve

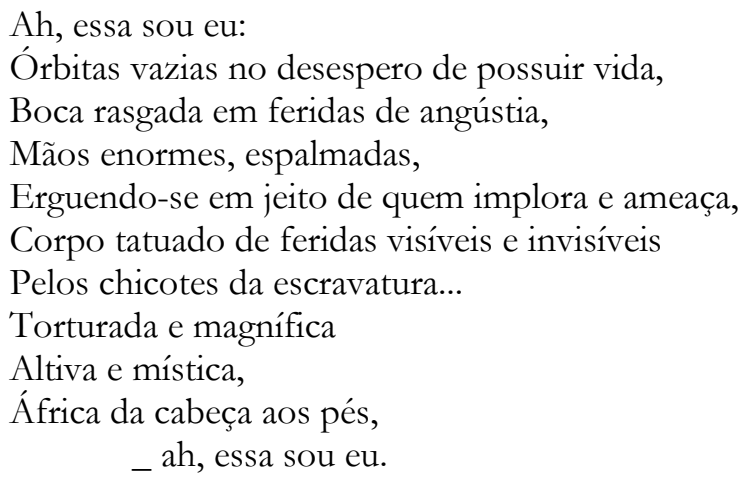

A violência sobre o corpo da mulher corresponde à violência sobre o corpo do continente africano, por cuja libertação a autora lutou como ativista, além de poetisa. Porém estas representações tardam anos a chegar a Portugal e ainda tardam em ser conhecidas, deixando espaço à permanência da visão estereotipada e sexualizada das mulheres. Mesmo assim, é possível interrogar a produção cultural desta altura, no intento de ver se a representação das mulheres sofreu uma mudança, tendo como primeiro termo de comparação as imagens de Rosa na Exposição Colonial de 1934.

Em Que se passa na frente, embora as imagens dos negros africanos sejam 
efetivamente inferiorizantes, os desenhos revelam uma complexidade na relação colono/colonizado. O colonizado ajuda o soldado português, mas também combate contra ele, organiza emboscadas e armadilhas e causa medo no inimigo. No caso da mulher negra africana, a representação não é assim tão diversificada, mas também parece ser diferente dos exemplos de Rosa na Exposição Colonial de 1934. Embora o corpo da mulher apare claramente estereotipado e sexualizado, as relações das personagens femininas com os soldados portugueses parecem mais complexas.

\section{O corpo-colónia na BD de Augusto Cid}

Augusto Cid é um dos cartunistas mais famosos de Portugal. Nasceu em 1941 e a sua obra torna-se célebre entre os anos 70 e 80, embora a sua publicação mais conhecida, nomeadamente Soares é Fish, venha a ser publicada em 1997 com o prefácio do mesmo Mário Soares, que na altura acabara o seu segundo mandato como Presidente da República Portuguesa. Os desenhos de Que se passa na frente (1973) são uma coleção dos seus trabalhos publicados na Revista Militar Luanda, na altura da comissão militar de Cid em Angola, entre 1966 e 1967. Os desenhos apresentam a vida militar na colônia de forma humorística, mas também crítica, evidenciando a absurdidade da guerra e a situação de constante estresse e perigo em que os soldados se encontravam. Por isso o livro não se integra perfeitamente com a representação da guerra colonial feita pelo regime, se pensarmos que até em 1973 Marcelo Caetano declarava:

Guerra Colonial? As Províncias Ultramarinas estão em paz e ninguém nelas contesta a sua integração na Nação Portuguesa. Percorre-se a Guiné, anda-se pela vastidão da terra angolana, desloca-se quem quer que seja de lés a lés de Moçambique e não encontra populações revoltadas. [...] A vida decorre, por toda a parte, tranquila e normal, num ambiente de trabalho e de entendimento exemplares. (apud CARVALHO, 1977, p. 108).

Todavia, a reflexão sobre a representação das mulheres nos impele a analisar o assunto desconstruindo as diferentes estratificações de poder. Se, como afirma Geraldine Moande, "colonialism is a gendered process" (MOANE, 1999, p. 37), podemos observar as diferenças entre as representações dos homens africanos e das mulheres africanas, apresentando os primeiros uma variedade de caricaturas negada às segundas. É assim que nos desenhos os negros podem ser soldados, rapazes, fotógrafos, engraxates etc... Vestem camisas, camisetas ou roupa militar e têm diferentes relações com os portugueses, sendo 
aliados, colaboradores ou inimigos no mato. Em particular destaca-se a figura 2: neste, como noutros desenhos, os africanos mostram uma grande capacidade de enganar os soldados portugueses. $\mathrm{Na}$ verdade, trata-se de uma novidade, se pensarmos que "antes do fim da ditadura [...] a opção foi pelo (quase) endeusamento dos combatentes portugueses" (CLETO E PINA, 2001, p. 20). Em particular, nessa perspectiva destaca-se O Ericeira, de Baptista Mendes, publicado em 1972, onde conta-se a história de um soldado português morto por uma explosão em Angola. Pelo contrário, nos desenhos de Cid, o português nunca é representado segundo o estereótipo do herói nacional e é possível dizer que a carga humorística dos desenhos é dirigida primariamente contra o mesmo exército português.

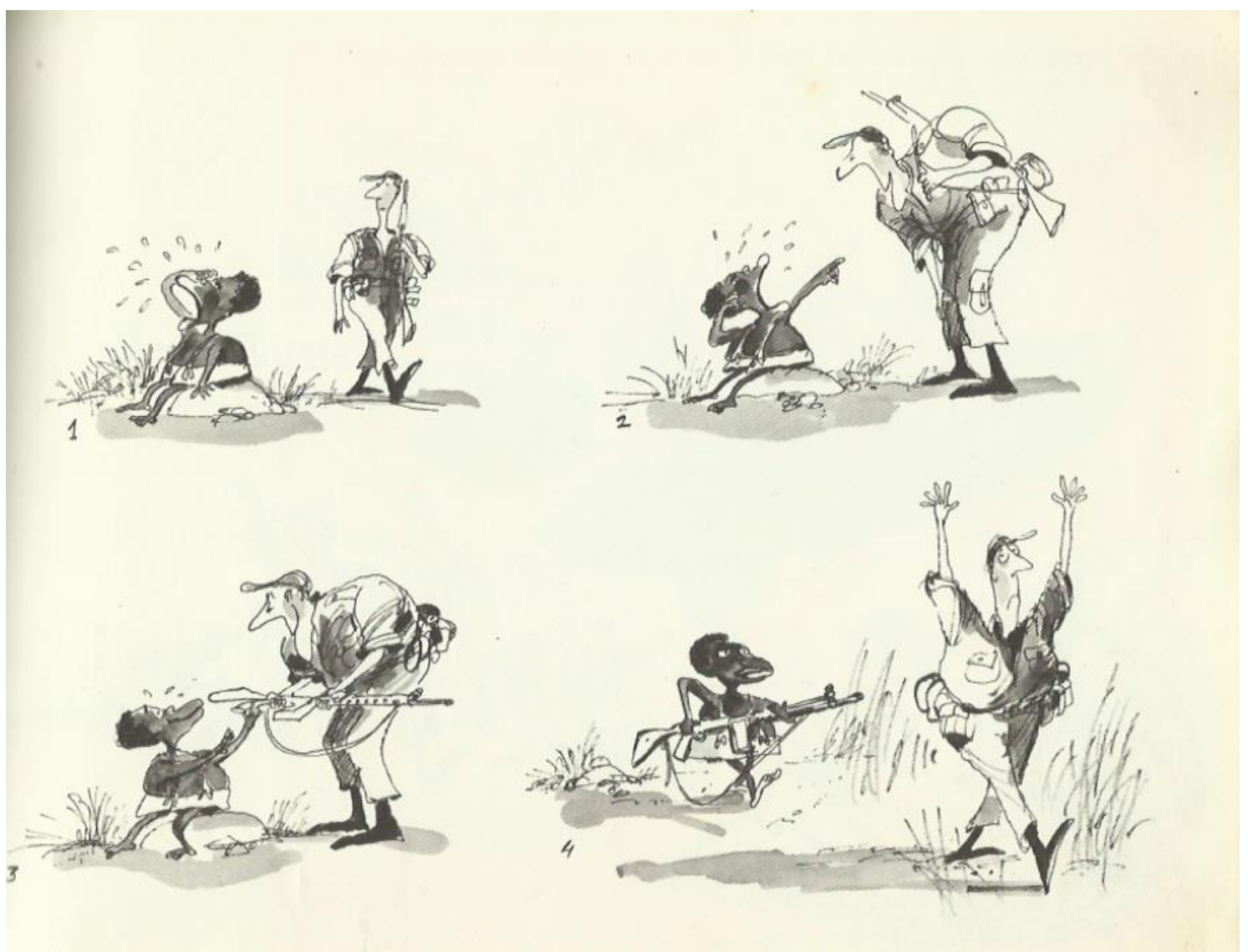

Figura 2

A variedade das representações dos negros africanos confirma talvez as reflexões de Luís Cunha que ilustra as linhas dominantes neste tipo de representação durante o Estado Novo. Cunha confronta as representações com os traços do processo colonial português, 
evidenciando as permanências (a inferiorização do negro) bem como as diferenças entre os três períodos por ele identificados, coincidindo o terceiro com a Guerra Colonial. Na verdade, neste último período emerge uma novidade significativa, ou seja, a variedade dos africanos representados, já não identificados por meio de um único estereótipo representativo, mas bem protagonistas de uma complexidade sintomática:

é [...] um negro 'criança grande' que aqui nos aparece. Alguém susceptível de ser enganado, quer dizer, cativado para más causas, mas que pode todavia regenerar-se, bastando, uma vez mais, aceitar ser submisso, já não tanto a um 'patrão' branco mas à nação portuguesa.

Nem todos os africanos encarnam, porém, o papel de criança grande. Existem os que são convictamente inimigos do país e aparecem nas histórias estigmatizados por comportamentos com que já nos encontrámos - como a agressividade gratuita mas também a cobardia ou a superstição - e existem outros que estão tão plenamente 'assimilados' que não correm o risco de ser seduzidos pelas ideias transportadas do exterior. (CUNHA, 1995, p. 17)

Porém, se olharmos para a representação do inimigo, emerge claramente uma conotação de gênero: o inimigo é homem e, desde uma perspectiva atenta exclusivamente à morfologia da representação, nada da complexidade, da profundidade, da dignidade reconhecidas aos homens sobrevive nas representações das mulheres africanas. $\mathrm{Na}$ verdade, parece que, nos desenhos de Augusto Cid, o imaginário estético das mulheres africanas não passou pelo mesmo analisado por Cunha, e que este tipo de representação atravessa intacta as décadas desde a Exposição Colonial de 1934 até os últimos anos do regime. Com a única exceção de uma mulher mais adulta, as outras mulheres negras são todas representadas com os abundantes seios descobertos, vestidas só com um pano enlaçado (ou, mais raro, com uma saia) à altura da cintura e outro a cingir os cabelos. Esta representação sexualizada torna-se ainda mais explícita se repararmos nas ações e palavras dos soldados portugueses representados: frente às mulheres negras os soldados atuam como "conquistadores", assim pode acontecer que não fique bem claro se uma emboscada é uma operação militar ou um encontro sexual (Figura 3). 


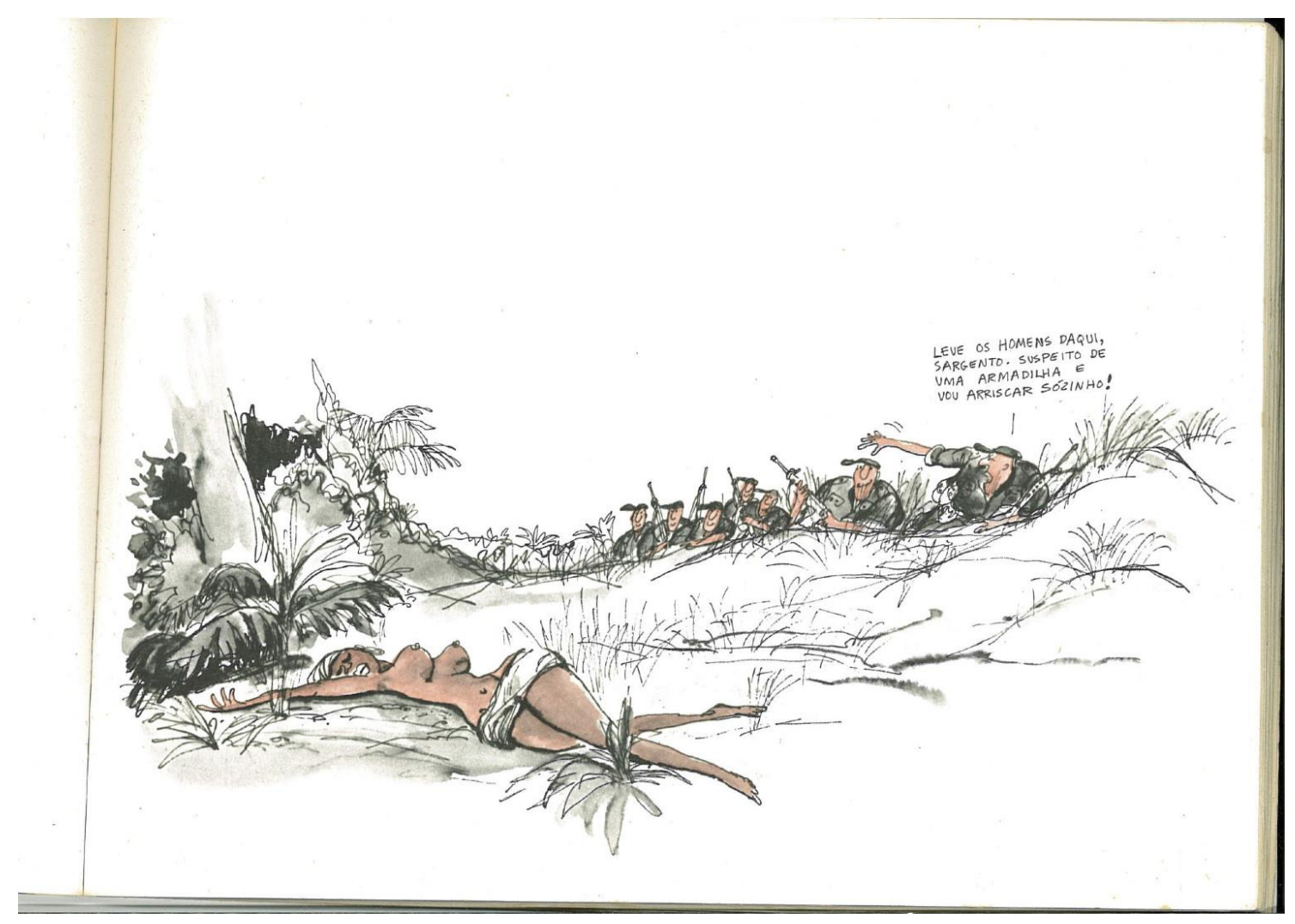

Figura 3

O melhor exemplo desta análise é o desenho que representa a chegada dos portugueses nas colônias (Figura 4): um enorme seio negro passa pela vigia do barco militar enquanto um soldado, indicando-o, grita “Terra à vista!”. A sobreposição é aqui completa: o corpo da mulher (ou melhor, uma parte desse), sexualizado e desejado, representa simbolicamente um território colonial.

Se num primeiro momento esta última imagem parece simplesmente reproduzir um imaginário funcional ao domínio português sobre as colônias e sua conotação sexual, a grandeza do seio sugere uma leitura mais complexa. É preciso lembrar que o objetivo destes desenhos é o de ironizar sobre os militares e, em particular, mostrar o que António Lobo Antunes definiu o "absurdo da guerra” (ANTUNES, 2008, p. 53): por isso o seio do desenho parece tão exagerado, que pouco se adapta às características dos mesmos soldados portugueses, como estes são representados neste e nos outros desenhos. A colônia parece assim algo demasiado grande, quase monstruoso, incompreensivel (segundo o duplo significado do verbo compreender, perceber/encerrar) para ser controlado, e os soldados portugueses (bem como os seus corpos) parecem totalmente inadequados ao objetivo. Adotando a perspectiva de Boaventura de Sousa Santos sobre a relação entre o 
Prospero/colonizador e o Caliban/colonizado e sobre o papel intermédio que Portugal teve ao longo dos séculos, é possível dizer que os soldados representados por Cid parecem Prosperos Calibanizados do império patriarcal.

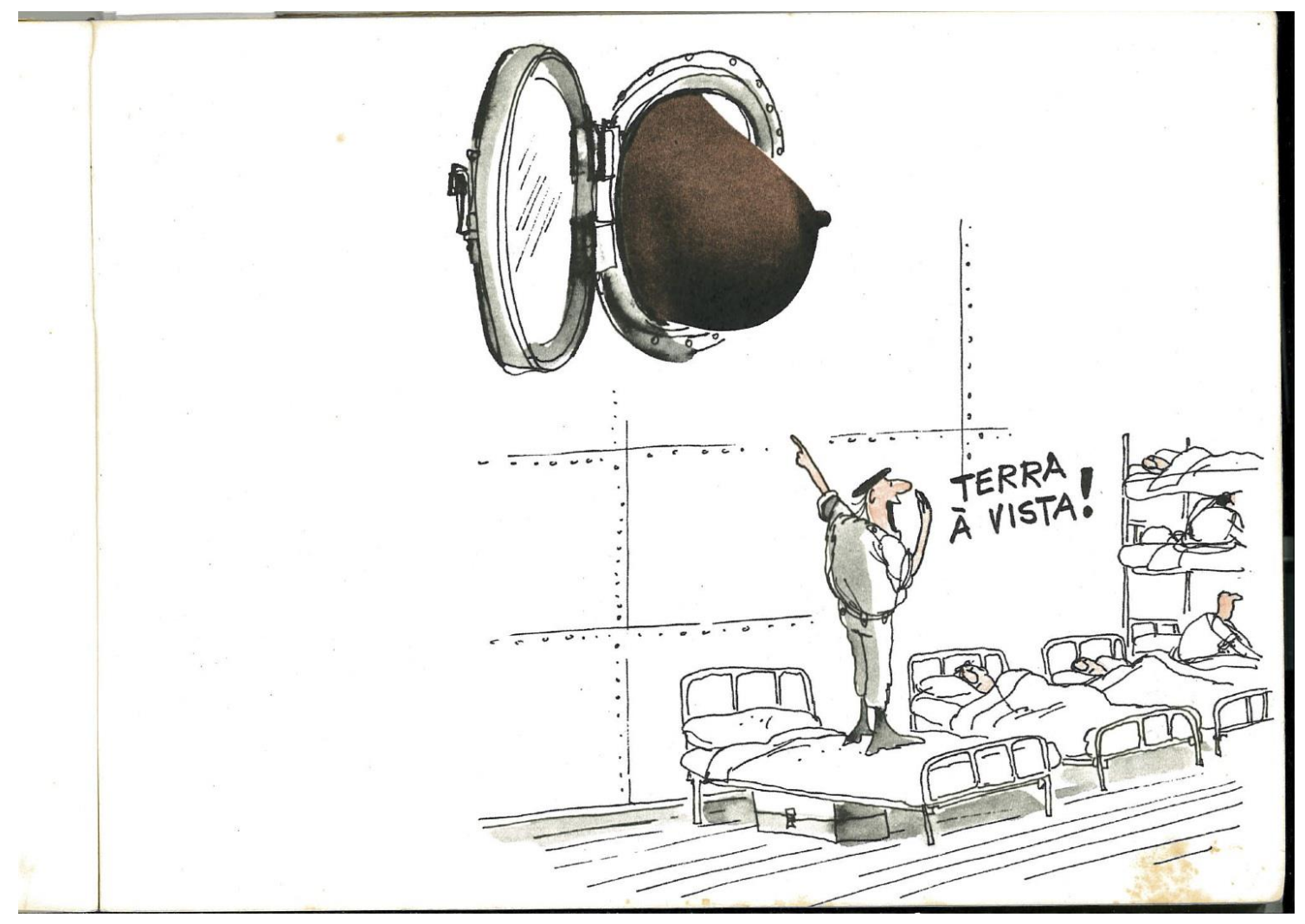

Figura 4

Se a nossa análise parece sugerir uma apologia das representações sexistas, é preciso sublinhar que nos encontramos frente a uma contradição presente não só nestes desenhos, mas na sociedade portuguesa, caracterizada, por um lado, pelo desejo de controle sobre as colônias e, por outro, pelo medo que a guerra produzia, que será a base das motivações do golpe militar do 25 de Abril. O fato é que a mesma guerra produz rupturas nos imaginários, mesmo que não sejam claras e lineares: os desenhos onde a mulher negra é representada como objeto sexual passivo são ainda a maioria, porém ao lado destes há outros nos quais, ainda que continuem sendo representadas como objetos sexuais, as mulheres negras conseguem escapar ao estereótipo da mulher complacente. É o caso das figuras 5 e 6: no primeiro caso o encontro amoroso fica adiado em função do que parece ser uma rígida norma social que prevê a aprovação da mãe da mulher; no segundo, a mulher é, feita 
exceção pela nudez, totalmente ocidentalizada, mostrando vontade de ler as páginas culturais do jornal. Também é preciso destacar outro elemento: a mulher negra fala, apesar do uso incorreto (segundo a perspectiva de um leitor português) da língua. Se, por um lado, isto pode ser funcional para criar um efeito humorístico, é verdade que o objeto central da ironia de Cid nestes dois desenhos é a surpresa/desilusão dos soldados portugueses em relação às suas próprias expectativas. O estereótipo parece assim conviver com uma visão mais complexa da mulher se compararmos com as imagens apresentadas na Exposição Colonial.

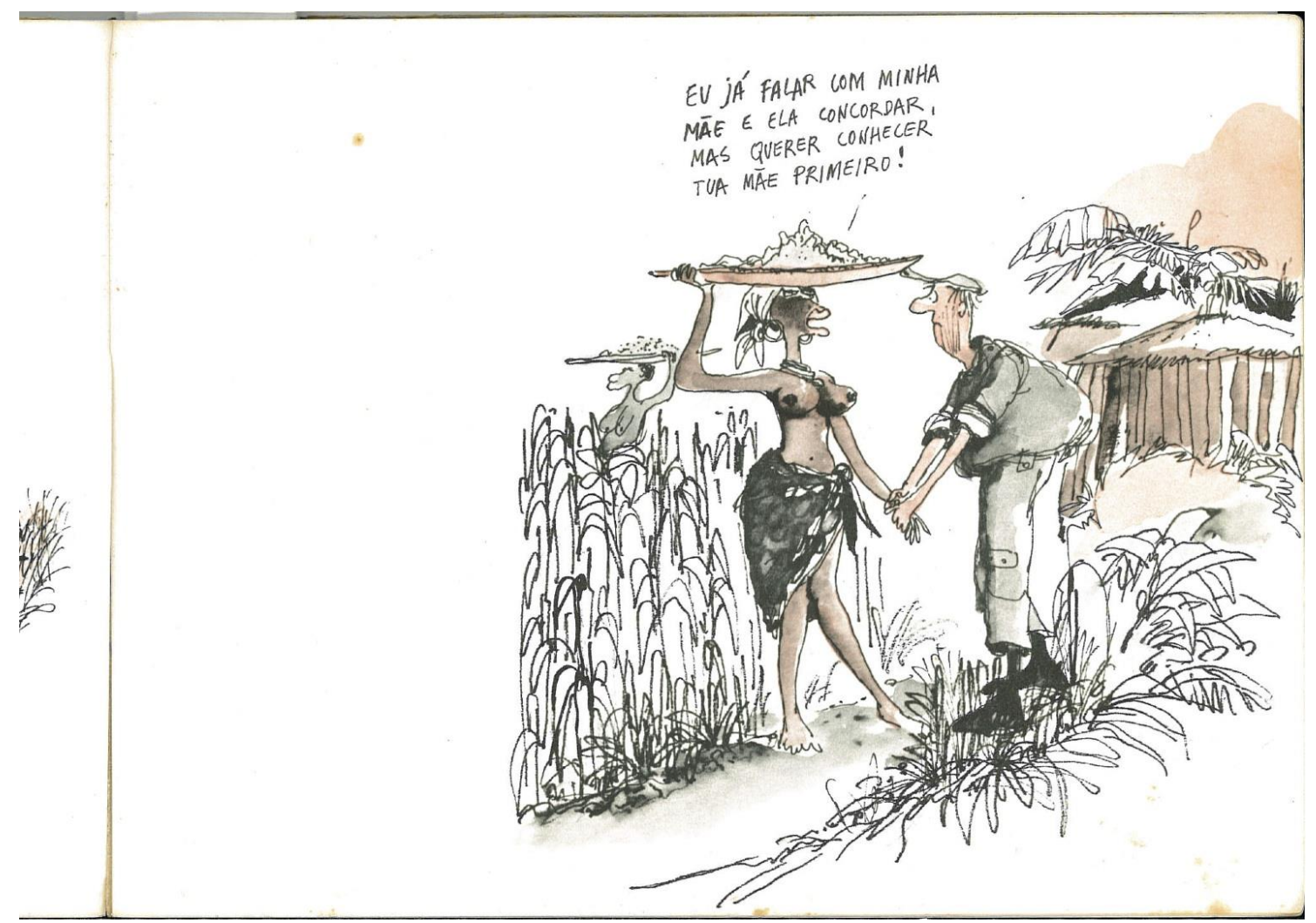




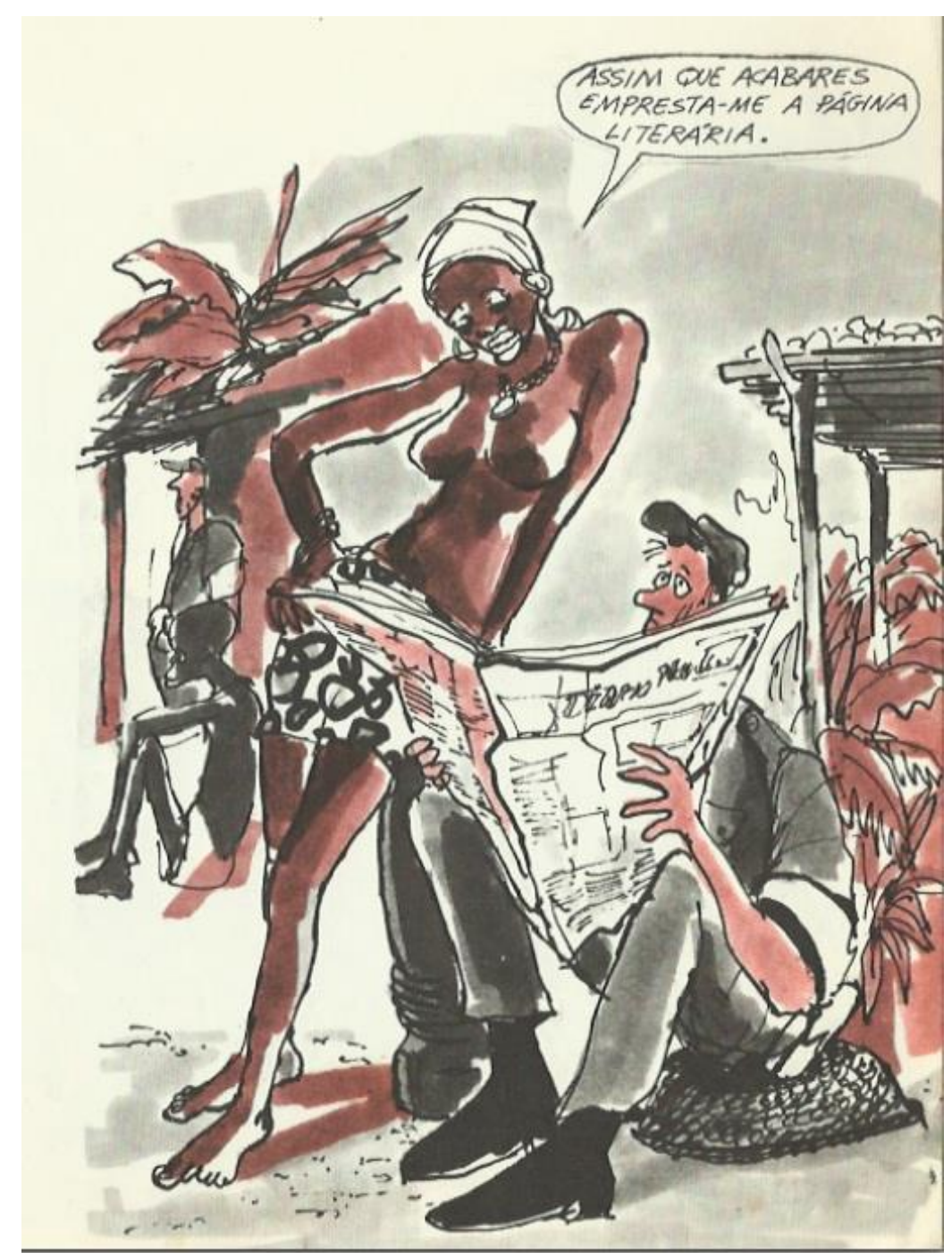

Figuras 5 e 6

O último desenho (Figura 7) mostra como a mulher negra traz um novo de conflito à sociedade portuguesa. Após dois anos na colônia, o soldado volta a Portugal e abraça a mãe. Atrás dele há uma mulher negra, obviamente seminua, com duas crianças e um macaco. Outra vez, embora a imagem reproduza o estereótipo da mulher negra (até com o macaco, sugerindo um imaginário bestializado), é a sua mesma presença em Portugal com dois filhos que representa uma novidade, também pelas palavras que o soldados endereça à mãe, estarrecida pelo que vê: "mãezinha, o seu menino chegou e acabaram-se todas as sua preocupações!". O efeito cômico é devido ao fato de a presença da mulher, dos filhos e do macaco ser, efetivamente, uma preocupação para a mãe do soldado, enquanto elementos desestabilizadores da normalidade da vida portuguesa durante o Estado Novo. Mas a imagem 
da mulher negra, com filhos, que acompanha o soldado português ao voltar a Portugal, é bastante atípica e entra em choque com as figuras das mulheres portuguesas que ficaram à espera dos maridos, constantemente preocupadas com a saúde deles. O corpo da mulher é, por isso, colônia enquanto lugar de conflito, presença não domesticada no imaginário e na administração de um país colonial. A mulher negra parece assim abrir um conflito no imaginário nacional português e a sua presença vem a ser o símbolo do retorno do que durante séculos foi excluído e identificado como Outro, compreendendo isto territórios, povos e corpos para humilhar e conquistar.

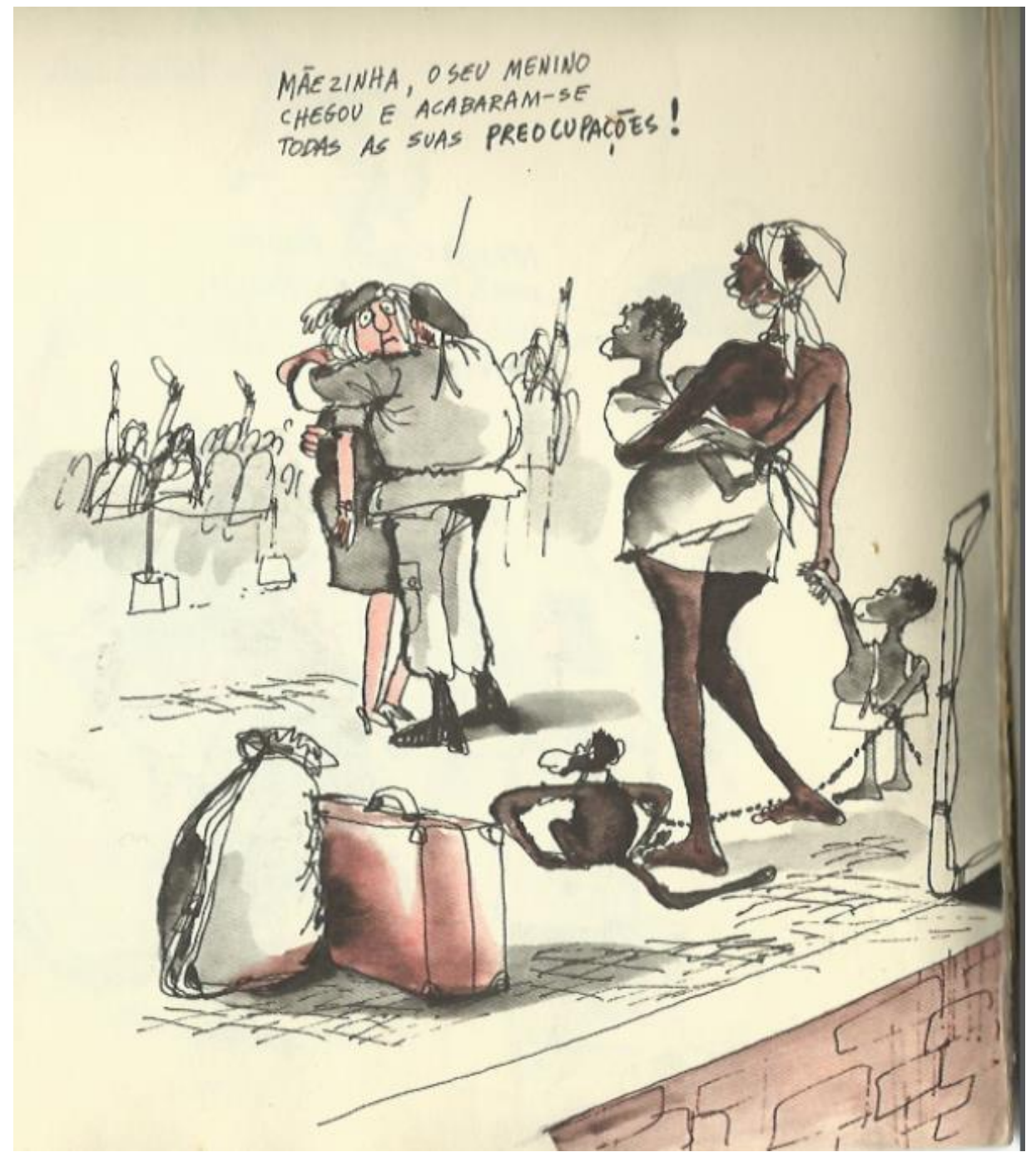

Figura 7

\section{Conclusão}

Obviamente a mudança da representação da mulher negra no imaginário português 


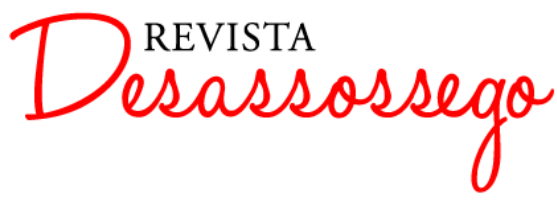

DESASSOSSEGO 17 | JUN/2017 | ISSN 2175-3180

DOI: http://dx.doi.org/10.11606/issn.2175-3180.v9i17p5-24

contemporâneo não é triunfal como poderia parecer na descrição das últimas linhas do parágrafo anterior. $\mathrm{O}$ estatuto preliminar deste artigo não permite reconstruir o mosaico completo das complexidades que se entrecruzam no assunto das representações das mulheres negras. De qualquer forma, no objetivo de chegar a interrogar o nosso presente, algumas sugestões nos proporcionam possíveis direções para investigar o assunto. Por exemplo, o romance O retorno (2011), de Dulce Maria Cardoso, mostra que os estereótipos podem "migrar" não só de um país para o outro, mas também de uma raça para a outra: o protagonista do romance, Rui, "retornado" de Moçambique em pleno PREC, descreve como as mulheres sofrem os estereótipos racistas e sexistas que os colonos endereçavam às colonizadas:

os rapazes de cá não querem namorar com as retornadas. Se for para gozar está bem mas para namorar não, os rapazes de cá dizem que as retornadas lá andavam com os pretos. E as raparigas de cá não querem ser amigas das retornadas para não serem faladas, as retornadas têm má fama, usam saias curtas e fumam nos cafés. (CARDOSO, 2011, p. 143)

$O$ Retorno parece assim sugerir que o racismo e o patriarcado não morreram com o fim da guerra colonial, mas, com permanências e rupturas, mudaram de forma nos anos seguintes. O mesmo Boaventura de Sousa Santos sugere que, em geral, as linhas de dominação do colonialismo continuam no neocolonialismo, mas que, no caso português, esta relação não se evidencia nas relações internacionais entre Portugal e suas antigas colônias, mas no colonialismo interno dos vários países. O mesmo Santos deixa aberta a dúvida sobre o presente: "the issue is whether and under what forms this identity is still being reproduced, now that Portugal has earned the periphery of Europe as its rightful place" (SANTOS, 2002, p. 20).

Se a ideia da mudança do colonialismo "externo" para colonialismo interno for confirmada, mais uma vez poderemos voltar à tese de Eduardo Lourenço (1998) segundo a qual Portugal parece não ter feito as pazes como seu trauma mais recente, o 25 de Abril e a complexidade que levou a esse evento. Dessa forma, o mito dos "portugueses suaves", bem como o da plurirracialidade aconflitual, permaneceriam até hoje como jogo e como forma de controle. Faz poucos anos que Portugal interroga-se sobre o tema do racismo e os modos como o país revela-se uma sociedade racista (HENRIQUES, BATISTA, 2016). Os movimentos globais contemporâneos nos impelem a abordar esse assunto a partir de 
uma perspectiva de gênero, para mostrar como se articulam as novas formas de domínio, quais são as suas relações com o passado e quais são as novas formas de resistência.

\section{Bibliografia:}

ANTUNES, António Lobo, Os cus de Judas. Lisboa: Leya, 2008.

AZEVEDO, Celia Maria Marinho de. Onda negra, medo branco. O negro no imaginário das elitesSéculo XIX. Rio de Janeiro: Editora Paz e Terra, 1987.

BARRENO, Maria Isabel; HORTA, Maria Teresa; COSTA, Maria Velho da. Novas cartas portuguesas. Lisboa: Dom Quixote, 2010.

CARDOSO, Dulce Maria. O retorno. Lisboa: Edições Tinta-da-China, 2011.

CID, Augusto. Que se passa na frente. Lisboa: Litografia de Portugal, 1973.

CID, Augusto. Soares é fish. Mem Martins: Europa-América, 1997.

CLETO E PINA, F. "BD portuguesa também contou lutas de libertação". Jornal de notícias, p. $20-21,21 / 05 / 2001$

COVA, Anne; PINTO, António Costa. "O Salazarismo e as mulheres. Uma abordagem comparativa”. Penélope, 17, 1997.

CUNHA, Luís. "A imagem do negro na BD do Estado Novo: algumas propostas exploratórias". Instituto de Ciências Sociais- Universidade do Minho, 1995.

DAVIS, Angela. Angela Davis: an autobiography. New York: Random House, 1974.

ESPANCA, Florbela. "Ás mães portuguesas". Em Obra poética. Lisboa: Presença, 2009.

FARRAJOTA, Marcos. Revisão. Bandas desenhadas dos anos 70. Cascais: Associação Chili com carne, 2016.

FANON, Frantz. Pele negra, máscaras brancas. Porto: A. Ferreira, 1972.

FONSECA, Maria Nazareth Soares. "O corpo feminino da nação". Scripta. Belo Horizonte, v. 3, n. 6, p. 225-236.

FOUCAULT, Michel. Microfisica do poder. Rio de Janeiro: Graal, 1979.

GALZIGNA, Mario. "Introduzione”. Em FOUCAULT, Michel, Storia della follia nell'età Classica. Milano: Bur Rizzoli, 2011

LOURENÇO, Eduardo. "Psicanalise mítica do destino Português". In: O labirinto da saudade. Psicanalise mítica do destino português. Lisboa: Dom Quixote, 1988.

LUKÁCS, György. O romance histórico. São Paulo: Boitempo, 2011. 


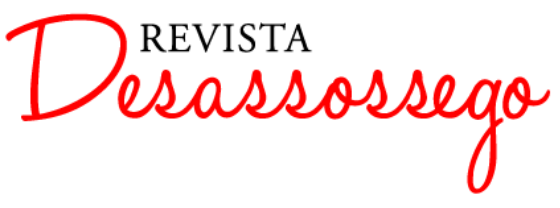

DESASSOSSEGO 17 | JUN/2017 | ISSN 2175-3180

DOI: http://dx.doi.org/10.11606/issn.2175-3180.v9i17p5-24

MIES, Maria. Patriarchy and accumulation on a world scale. Women in the international division of labour. London: Zed Books, 1999.

MENDES, Baptista. O Ericeira. Guiné Bissau: Revista da Armada, 1972.

MILLER, Jean Baker. Toward a New Psychology of Women. London: Penguin, 1986.

MOANE, Geraldine. Gender and colonialism. A Psychological Analysis of oppression and Liberation.

New York: Palgrave Macmillan, 1999.

MORAIS, Isabel. "«Little Black» Rose at the 1934 Exposição Colonial Portuguesa". In: BOISSEAU, TJ - MARKWYN, A.M. (cur). Gendering the fairs. Histories of women and gender at world fairs. University of Illinois Press, 2001.

NEVES, Helena. "O Estado Novo e as mulheres". Lisboa: CML/Biblioteca Museu República e Resistência, 2001.

OSÓRIO, Ana Castro. "Ser português". In: Às mulheres portuguesas. Lisboa: Editora Viúva Tavares Cardoso, 1905.

PIÇARRA, Maria do Carmo. "Pele negra ou pele branca: máscara(s) da mulher imaginada pelo cinema colonial". Observatorio (OBS*) Journal, vol. 9, n. 2, 2015.

RIBEIRO, Margarida Calafate. "África no feminino. As mulheres e a guerra colonial". Revista crítica de ciências sociais, 68, p. 7-29, 2004.

RICOEUR, Paul. A memória, a história, o esquecimento. Campinas, São Paulo: Ed. Unicamp, 2008.

SAID, Edward W. Orientalism. London: Penguin Book, 2003.

SPIVAK, Gayatri Chakravorty. A critique of post-colonial reason. Toward a bistory of the vanishing present. Harvard Univeristy Press, 1999.

SANTOS, Boaventura de Sousa. "Between Prospero and Caliban: colonialism, postcolonialism, and inter-identity". Luso-Brazilian Review, n. 39/2, 2002.

SOUSA, Noêmia de, "Se me quiseres conhecer". In: Sangue negro. Maputo, AEMOAssociacião dos escritores Moçambicanos, 2001.

TAVARES, Maria Manuela Paiva Fernandes. Feminismos em Portugal (1947 -2007). Coimbra: Universidade Aberta, 2008.

WHITE, Hayden. Metahistory. The historical imagination in the XIX century in Europe. London: John Hopkins Univeristy Press, 1973. 


\section{Páginas web:}

DAVIS, Angela, “Here's the full transcript Angela Davis's Women’s March Speech”, 21/01/2017. Disponível, em: http://www.elle.com/culture/career-politics/a42337/angeladavis-womens-march-speech-full-transcript/

HENRIQUES, Joana Gorjão; BATISTA, Fredrico, "O que é o racismo?", Público, 2016.

Disponível em: https://www.publico.pt/racismo-em-portugues/o-que-e-o-racismo

Non una di meno, "8 punti per l'8 marzo: non un'ora in meno di sciopero", 8/02/2017.

Disponível em: https://nonunadimeno.wordpress.com/2017/02/08/8-punti-per-18-

marzo-non-unora-meno-di-sciopero

Queering style, "8M não me calo! Paralicação internacional das mulheres- Lisboa", 5/03/2017. Disponível em http://queeringstyle.com/evento/8m-nao-me-calo-paralisacaointernacional-de-mulheres-lisboa/ 